\title{
LONG SURVIVAL WITH INFERIOR VENA CAVA DRAINING INTO LEFT ATRIUM
}

\author{
BY \\ D. L. GARDNER AND LESLIE COLE \\ From Addenbrooke's Hospital and the Department of Pathology, University of Cambridge
}

Received September 3, 1954

Developmental anomalies of the inferior vena cava are not infrequent. The majority cause no circulatory disturbance, but a small number result in veno-arterial communications that allow only a short period of postnatal life (Taussig, 1947).

Clinical and anatomical details are given below of an unusual case in which termination of the inferior vena cava in the left atrium was the only congenital abnormality affecting the circulation. Cyanosis was constantly present, there were few signs of heart disease and the patient lived actively for 32 years. The available details of her history, the physical signs, and the investigations performed are sufficient to assist in the recognition of future cases and are therefore described fully. We were unable to find previous records of a similar case or of an identical anatomical defect.

\section{CASE History}

The patient was a married woman who died in 1953 at the age of 32 . At the age of 4 years she had pneumonia and was subsequently noticed to be cyanosed. At 7 congenital heart disease was diagnosed. She had no symptoms apart from slight breathlessness on exertion, and was able to live a normal life and play games at school. From the age of 14 she worked as a domestic servant and college bedmaker until she married at 18. At 19 she became pregnant but the child died shortly after birth. Thereafter she had a succession of miscarriages at 4,3 , and 5 months respectively, and at the age of 23 was seen by one of us (L.C.) when she was again 24 weeks pregnant. At that time she suffered from considerable breathlessness on exertion and some swelling of the ankles but her condition was otherwise good. She was sturdy and wellproportioned and weighed $8 \mathrm{st} .12 \mathrm{lb}$. (56 kg.).

Examination showed severe cyanosis and clubbing of the fingers, but no other abnormalities. No murmurs were heard then or on any subsequent occasion and the heart sounds were normal. The blood pressure was 140/90, and the urine was normal. X-ray and screening showed no abnormality of the heart or lungs (Fig. 1). The cardiogram showed inversion of TII and deep inversion of TIII but was otherwise normal (Fig. 2). Blood count showed: red cells 6.9 million per cu. $\mathrm{mm}$. and hæmoglobin $17 \mathrm{~g}$. per $100 \mathrm{ml}$. Wasserman reaction negative. The pregnancy was allowed to continue and a normal full-term infant was born who still survives. She made a good recovery and appeared none the worse for her confinement.

A few weeks later she attended Ophthalmological Out-Patients with embolism of a branch of the right retinal artery, but did not again visit the Cardiac Clinic until the age of 28, when the clinical symptoms and signs were unchanged (red cells 6.4 million per cu. mm., and hæmoglobin $19.4 \mathrm{~g}$. per $100 \mathrm{ml}$.; circulation time-arm-to-lung $17 \mathrm{sec}$., arm-to-tongue $24 \mathrm{sec}$.).

At 29 she again became pregnant, and was readmitted with toxæmia of pregnancy, blood pressure 180/120, and severe albuminuria. Her symptoms cleared up after a miscarriage, the fotus weighing $2 \frac{1}{2} \mathrm{lb} .(1 \cdot 1 \mathrm{~kg}$.), and the blood pressure fell to $130 / 70$. Soon after this she developed tonsillitis followed by congestive heart failure and multiple pulmonary emboli. Pyrexia was prolonged and although blood cultures were sterile she was given 146 mega units of penicillin in six weeks. She again made a gradual recovery and was finally discharged eight months after her confinement and was soon well enough to do housework again.

Subsequent progress was uneventful and she continued to lead a comparatively active life until the age of 32 years. Then one day while stretching up to a high shelf she collapsed suddenly and died. 


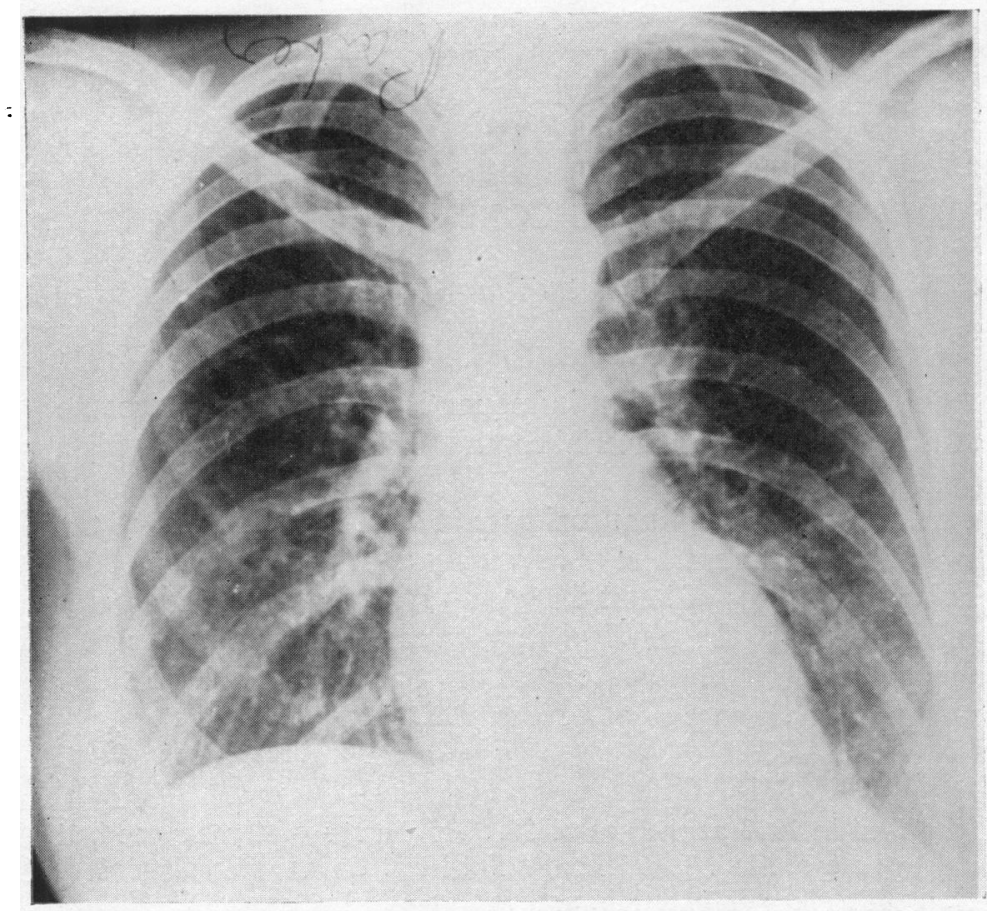

Fig. 1.-X-ray of chest at the age of 23 years.

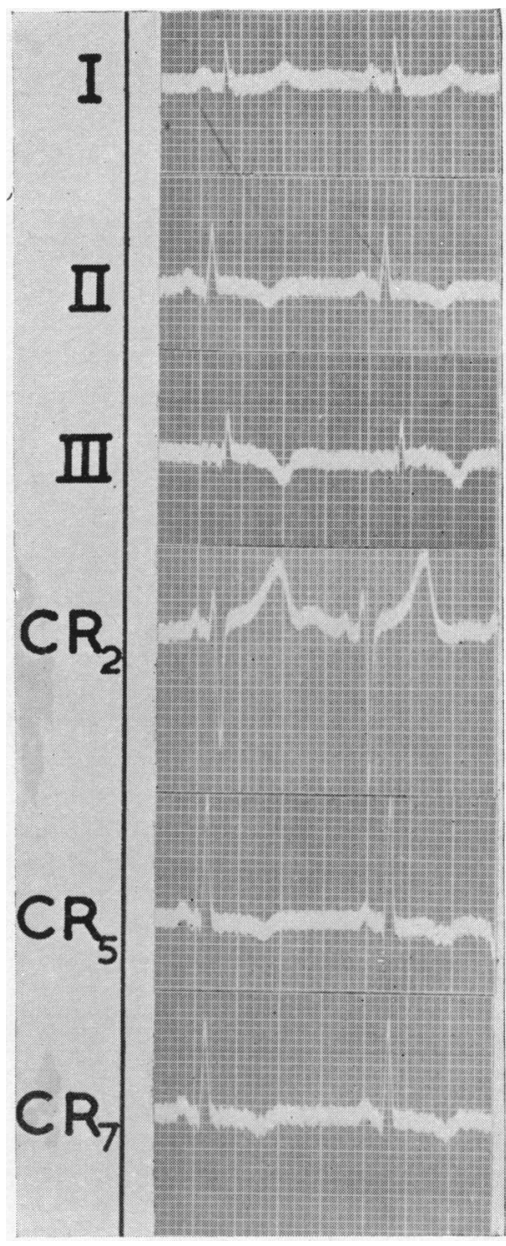

FIG. 2.-Electrocardiogram, showing inversion of TII and deep inversion of TIII at the age of 29 when the blood pressure was $180 / 120$ from toxæmia of pregnancy. The limb leads were identical at 23 years of age.

\section{NECROPSY REPORT}

Necropsy was performed 24 hours after death. The body was that of a well-nourished young woman (weight $55.5 \mathrm{~kg}$.), and showed generalized cyanosis which was most pronounced in the extremities. There was slight clubbing of all fingers and toes.

The heart occupied its normal position and weighed $450 \mathrm{~g}$. The inferior vena cava passed proximally from the upper surface of the diaphragm and entered the left atrium. At its termination this vessel measured up to $3.5 \mathrm{~cm}$. in diameter and up to $0.5 \mathrm{~cm}$. in thickness (Fig. 3). (All measurements were confirmed on the preserved specimen.) The anatomical relationships of the veins below the diaphragm were normal, the inferior vena cava lying to the right of the anterior surface of the vertebral column and being formed by the union of two common iliac veins. The hepatic veins were considerably dilated. The superior vena cava $1.5 \mathrm{~cm}$. in diameter, was joined by a greatly dilated azygos vein and entered the right atrium. Fibrous tissue obliterated the left internal jugular and the left innominate veins. The subclavian veins were not examined. 


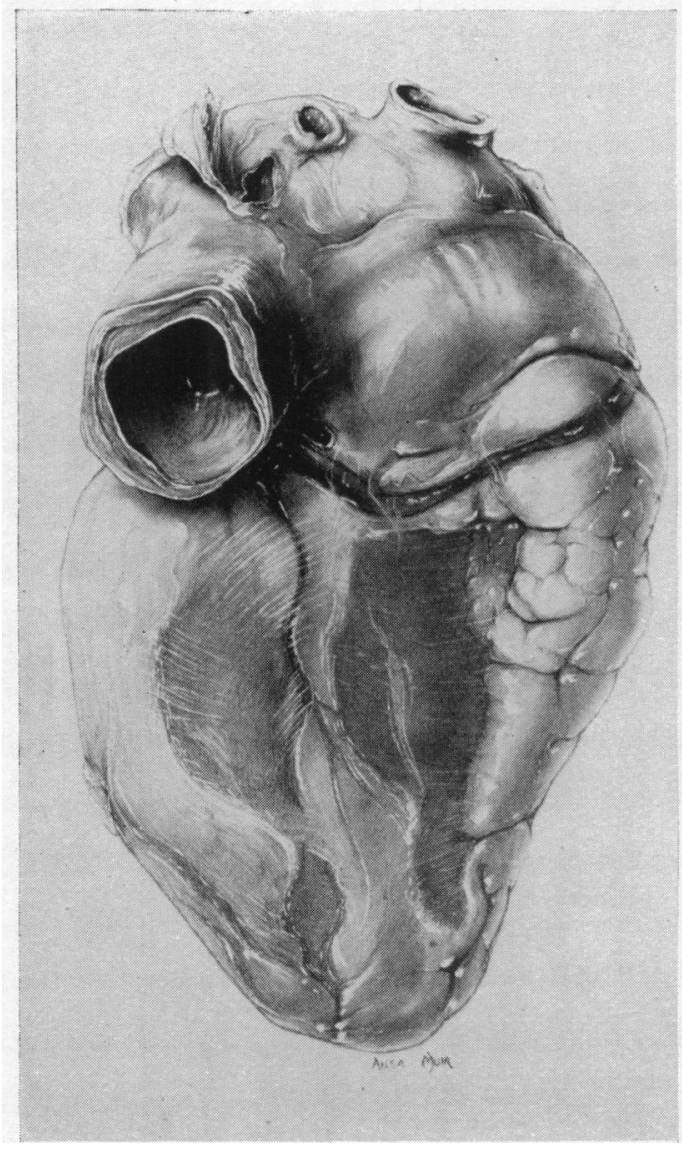

Fig. 3.-Dorsal view of the heart, showing the left inferior vena cava.

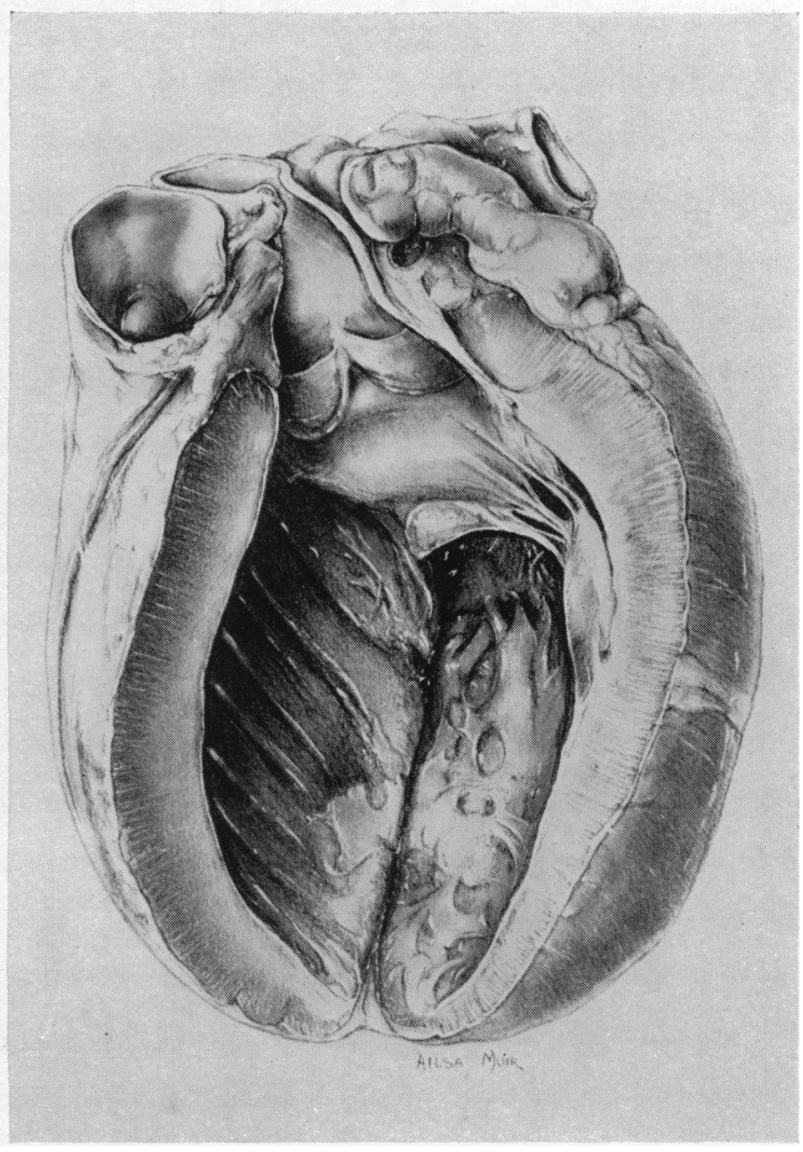

FIG. 4.-The opened left ventricle with the old infarct.

The coronary sinus (diameter $0.7 \mathrm{~cm}$.) occupied its normal site and drained to the right atrium: no valve guarded its orifice. The oblique vein of the left atrium could not be defined. The left atrium, slightly dilated and considerably hypertrophied, received three pulmonary veins, two right and one left. The mitral valve was normal (circumference $8.6 \mathrm{~cm}$.). The right atrium was unusually small and received only the superior vena cava and the coronary sinus. The tricuspid valve was small (circumference $10 \mathrm{~cm}$.) but anatomically normal. The interatrial septum was complete and a probe could be passed neither from the left to the right atrium nor in the reverse direction. Although the fossa ovalis was of normal size, the annulus fossa ovalis was postero-inferior in position (Fig. 5). The crista terminalis could not be identified.

The left ventricular wall was hypertrophied and measured up to $1.8 \mathrm{~cm}$. in thickness except in its posterior part where fibrosis, slight thinning, and aneurysmal dilatation indicated the site of an old healed infarct (Fig. 4). The aorta was perhaps slightly smaller than is usual in a woman of this age (circumference immediately above the aortic valve $8.1 \mathrm{~cm}$.). The aortic valve had three cusps. The coronary arteries, which were entirely free from atheroma, took origin from the anterior and left posterior aortic sinuses. Near the termination of the right coronary artery, at a point corresponding in distribution to the healed infarct, was a limited zone of intimal roughening. The right ventricle was small but the pulmonary artery appeared normal (circumference $8.6 \mathrm{~cm}$.). The ductus arteriosus was obliterated. The condition of the circulation is shown diagrammatically in Fig. 6. 


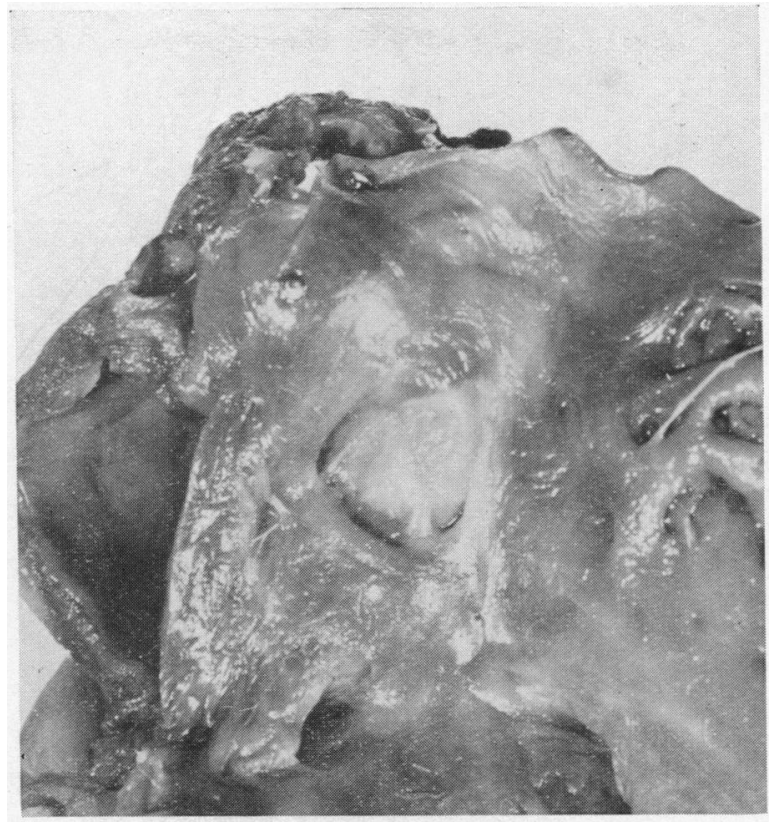

Fig. 5.-The interatrial septum, with the unusual fossa ovalis, the annulus being postero-inferior.

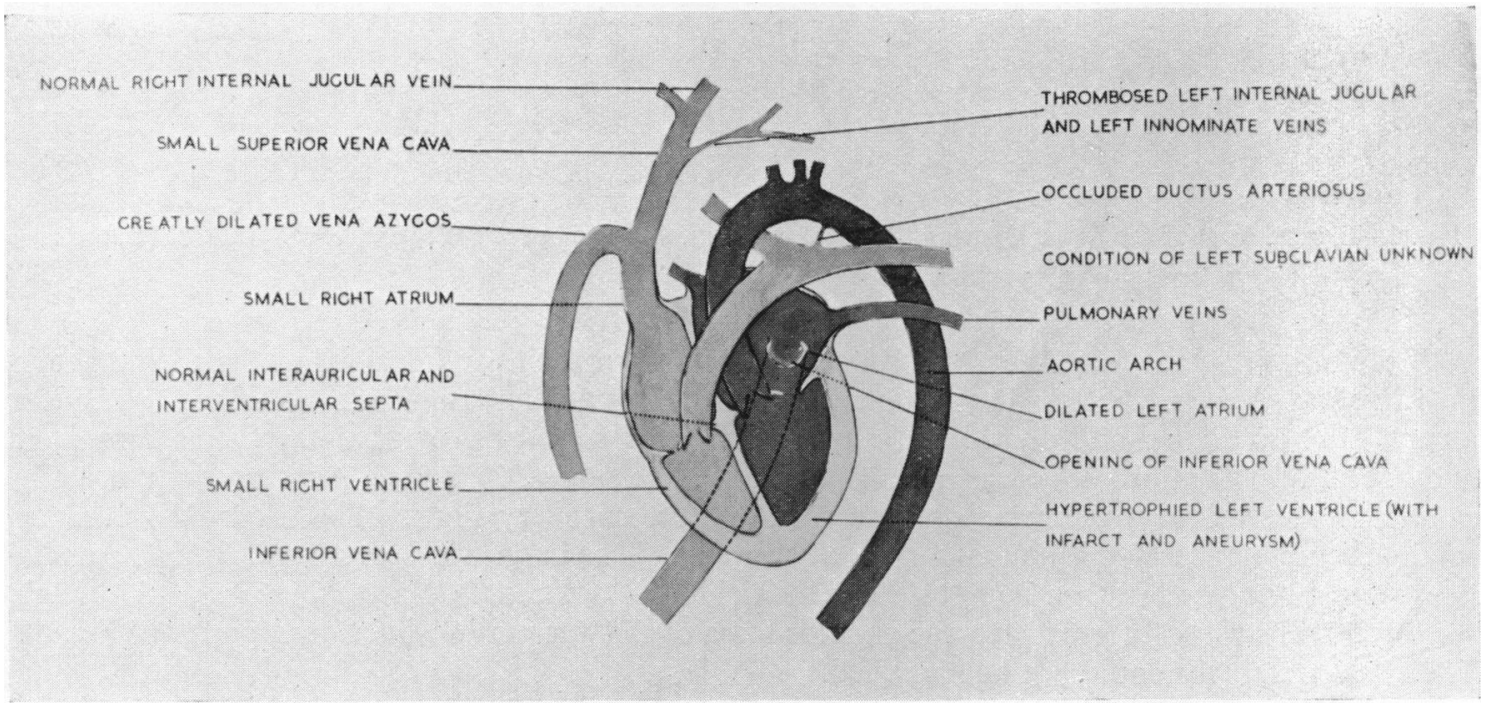

FIG. 6.-A diagram of the circulation, showing the inferior vena cava entering the left atrium.

The right lung weighed $500 \mathrm{~g}$. and the left $425 \mathrm{~g}$. The pleural cavity over the anterior border of the left lower lobe was obliterated by fibrous adhesions which covered an area of $2 \times 3 \mathrm{~cm}$. Beneath this area was a zone of grey-white tissue, representing an old infarct. The liver $(1650 \mathrm{~g}$.) was covered by a smooth capsule, and the arrangement of the hepatic lobes, which were intensely congested, was normal. The spleen was firm and congested $(270 \mathrm{~g}$.). At the junction of the inferior and lateral surfaces of the right frontal lobe of the brain (weight $1290 \mathrm{~g}$.) $1 \mathrm{~cm}$. anterior to the lateral fissure, was 
a slightly yellow area of cortical softening, $2 \mathrm{~cm}$. in diameter. The cerebral blood vessels were normal and free from atheroma. The right kidney weighed $155 \mathrm{~g}$., the left $160 \mathrm{~g}$. The bone marrow of the right femur was congested through its extent and microscopy revealed erythroid hyperplasia.

\section{Discussion}

Very many variations in the developmental pattern of the inferior vena cava have been described, but few of the resulting anomalies are significant causes of congenital heart disease (Taussig, 1947; Brown, 1950; and Schnitker, 1952). Occasionally the left superior and inferior venæ cavæ have been found to drain together into the left atrium, but in these instances the circulation has been maintained by patency of the interatrial septum.

In the case described the principal clinical features were the cyanosis and clubbing of the fingers in the absence of murmurs or cardiac enlargement, and the capacity to lead an active life in spite of repeated pregnancies. She differed from most cyanotic patients with congenital heart disease in that she showed no evidence clinically or radiologically of enlargement of the right ventricle or of generalized cardiac enlargement. Repeated screening also suggested that the left ventricle was within the limits of normal. The cardiogram showed the same changes in limb leads at the age of 22 as at 29. The tendency to embolism was probably the result of her toxæmia of pregnancy and of the infections that followed it. Although the site of origin of the emboli is unknown, both systemic and pulmonary emboli may have originated from the same source.

No diagnosis that would embrace all the findings was made during life. The diagnosis of an atypical Eisenmenger's complex was considered but the combined absence of murmurs and of cardiac enlargement rendered this unlikely. In view of her age when she was first seen further investigations did not appear to be justified, even had the patient been willing. Angiocardiography and cardiac catheterization via the leg veins would appear to be the most likely method of establishing the diagnosis during life in a future case.

The developmental abnormality was confined to the proximal (hepato-cardiac) segment of the inferior vena cava (Hamilton et al., 1945; Arey, 1946), which normally represents the termination of the right vitelline vein (McClure and Butler, 1925) and, in the case described, drained blood to the left side of the heart instead of the right (Fig. 6). Venous blood therefore entered the systemic circulation resulting in constant reduction of the arterial oxygen saturation. The presence of a dilated azygos vein, however, suggests that a significant volume of venous blood may have returned to the right atrium. Both interatrial and interventricular septa were complete but the structure of the fossa ovalis, with the anomalous postero-inferior position of the annulus, cannot be explained.

\section{SUMMARY}

A case of cyanotic congenital heart disease without cardiac enlargement or murmurs is described. The patient retained considerable capacity for effort until sudden death occurred at the age of 32 years.

Necropsy revealed a congenital abnormality of the inferior vena cava which drained into the left atrium. No other developmental abnormalities of significance were found.

We wish to thank Professor J. D. Boyd for his advice on the nature of the anatomical abnormality, and Dr. A. M. Barrett for much help with the dissection of the specimen. We are grateful to Miss Sylvia Westoby for the photographs and to Miss Ailsa Muir for the drawings.

This report is based on a communication presented to the British Cardiac Society in April, 1954. The anatomical specimen was demonstrated to the Pathological Society of Great Britain in January, 1954.

\section{REFERENCES}

Arey, L. B. (1946). Developmental Anatomy. Philadelphia.

Brown, J. W. (1950). Congenital Heart Disease. London.

Edwards, E. A. (1951). Angiology, 2, 285.

Hamilton, W. J., Boyd, J. D., and Mossman, H. W. (1945). Human Embryology. Cambridge.

McClure, C. F. W., and Butler, E. G. (1925). Amer. J. Anat., 35, 331.

Maxwell, E. V., and Erwin, G. S. (1928). J. Anat., 62, 184.

Schnitker, M. A. (1952). Congenital Anomalies of the Heart and Great Vessels. New York.

Taussig, H. B. (1947). Congenital Malformations of the Heart. New York. 